\title{
MAPPING CHANGES AND DAMAGES IN AREAS OF CONFLICT: FROM ARCHIVE C-BAND SAR DATA TO NEW HR X-BAND IMAGERY, TOWARDS THE SENTINELS
}

\author{
Deodato Tapete $^{(1,2)}$, Francesca Cigna ${ }^{(2)}$, Daniel N.M. Donoghue ${ }^{(1)}$, Graham Philip ${ }^{(3)}$ \\ ${ }^{(1)}$ Department of Geography, University of Durham, Lower Mountjoy, South Road Durham, DH1 3LE, UK, \\ Email:deodato.tapete@durham.ac.uk,deodato@bgs.ac.uk \\ ${ }^{(2)}$ British Geological Survey, Natural Environment Research Council, Keyworth, Nottingham, UK \\ ${ }^{(3)}$ Department of Archaeology, University of Durham, Lower Mountjoy, South Road Durham, DH1 3LE, UK
}

\begin{abstract}
On the turn of radar space science with the recent launch of Sentinel-1A, we investigate how to better exploit the opportunities offered by large C-band SAR archives and increasing datasets of HR to VHR X-band data, to map changes and damages in urban and rural areas affected by conflicts. We implement a dual approach coupling multi-interferogram processing and amplitude change detection, to assess the impact of the recent civil war on the city of Homs, Western Syria, and the surrounding semi-arid landscape. More than 280,000 coherent pixels are retrieved from Small BAseline Subset (SBAS) processing of the 8year-long ENVISAT ASAR IS2 archive, to quantify land subsidence due to pre-war water abstraction in rural areas. Damages in Homs are detected by analysing the changes of SAR backscattering $\left(\sigma^{0}\right)$, comparing 3m-resolution StripMap TerraSAR-X pairs from 2009 to 2014. Pre-war alteration is differentiated from war-related damages via operator-driven interpretation of the $\sigma^{0}$ patterns.
\end{abstract}

\section{INTRODUCTION}

Space remote sensing is nowadays widely recognised as doable and cost-effective solution to assess the condition of cultural heritage and urban assets in areas of conflict [1] or affected by looting [2-3].

This is mainly owing to the opportunity offered by satellite imagery to overcome the constraint of site accessibility. Given the level of detail required by the end-users, high spatial resolution is the key property that normally makes optical and multispectral data the preferred option.

On the other side, the availability of historical imaging records is compulsory to undertake change detection and time series analysis. In this sense, the scientific community across the world has benefitted greatly from the global coverage of Synthetic Aperture Radar (SAR) data stacks provided by the first generation of ESA satellites. Second generation spaceborne SAR sensors such as those onboard the TerraSAR-X constellation have brought radar remote sensing at a level of spatial resolution comparable to that of optical imagery, and recently opened new perspectives in urban and heritage applications requiring high definition of objects on the ground at short temporal intervals.

\section{RESEARCH AIMS}

On this turn of urban and archaeological remote sensing, this research aims to evaluate the specific contribution that SAR and Interferometric SAR (InSAR) can add to monitor and map surface changes due to both natural and human-induced processes in semi-arid regions (e.g., overexploitation of water resources). In particular, we explore how baseline environment characterisation via archive ERS-1/2 and ENVISAT ASAR imagery can be combined with damage assessment based on HR to VHR X-band data.

\section{CASE STUDY: HOMS, SYRIA}

This paper presents the ongoing work over Homs, the third largest city of the country in Western Syria, and the surrounding areas, with particular interest in the village of Al-Qusayr and the rural district along the Wadi ar-Rabiya (Fig. 1).

Since March 2011, Homs has been hugely affected by the Syrian civil war. Shelling destroyed several buildings and damaged heritage assets, and some of the town quarters were heavily bombed, such as Bab Amr in the western part of Homs in February 2012.

In the countryside, the war impacted water supply systems used to support local agriculture. Several pipelines were cut off, thereby causing a significant reduction of the irrigated fields. These landscape changes added on existing anthropogenic impact on those areas where groundwater abstraction is claimed to have caused land subsidence in the last decades.

\section{INPUT SAR DATA}

We used the following input data to cover the whole urban setting and outskirts of Homs, as well as the rural region north and south of the city (Fig. 1):

(i) 36 ENVISAT ASAR images acquired along track 307 and descending passes throughout the period $31 / 12 / 2002$ to $31 / 08 / 2010$, with time lapse averagely equal to the nominal repeat cycle of 35 days and some gaps up to 315 days; these data were accessed via the Cat.1 id 28439 project "Land subsidence and archaeological remote sensing in Syrian sites with multi-temporal InSAR processing and radar 
interpretation of ERS-1/2 and ENVISAT SAR archive imagery";

(ii) TerraSAR-X and TanDEM-X archive and new acquisitions from 2008, granted by the German Aerospace Centre (DLR) in the framework of TSXNew-Modes-2013 LAN2377 project "TerraSAR-X Staring Spotlight mode for damage assessment, looting monitoring and prospection of archaeological features in semi-arid environment", including 3-m resolution StripMap (SM) images, as well as the novel beam mode referred to as 'Staring Spotlight' (ST), with achievable azimuth resolution of $0.24 \mathrm{~m}$.

\section{FROM ARCHIVE C-BAND SAR DATA ...}

We processed the ENVISAT ASAR time series by implementing the low-pass SBAS technique [4].

After precise co-registration, a subset centred at $36.8^{\circ} \mathrm{E}$, $34.7^{\circ} \mathrm{N}$ was selected. Multi-looking was undertaken using factors of 20 and 4 in azimuth and range respectively, and $\sim 100 \mathrm{~m}$ by $100 \mathrm{~m}$ ground resolution pixels were obtained. 136 small baseline differential interferograms were computed, using perpendicular baseline threshold of $200 \mathrm{~m}$ and temporal baseline $<4$ years.

More than 280,000 coherent pixels have been identified using a pixel coherence threshold of 0.25 (Fig. 1). As expected, high measurement densities are located over the urban settlements and infrastructure, the major of which is Homs town and secondarily the various villages in the outskirts. Over a total urban area of $\sim 87$ $\mathrm{km}^{2}$, SBAS processing identified more than 5,400 pixels, hence $\sim 62$ pixels $/ \mathrm{km}^{2}$.

Spatial distribution of coherent pixels across the subset appears to have been influenced by the diverse backscattering properties of the local lithologies, with marked discrimination between marly valleys and basalt outcrops [5]. This is accounted for among the parameters that can have an effect on the accuracy of the deformation analysis.

The ongoing work aims to correlate the spatial distribution of Line-Of-Sight deformation estimates with the hydrogeological setting of the areas where drop-down of the water table has been observed by the local community.

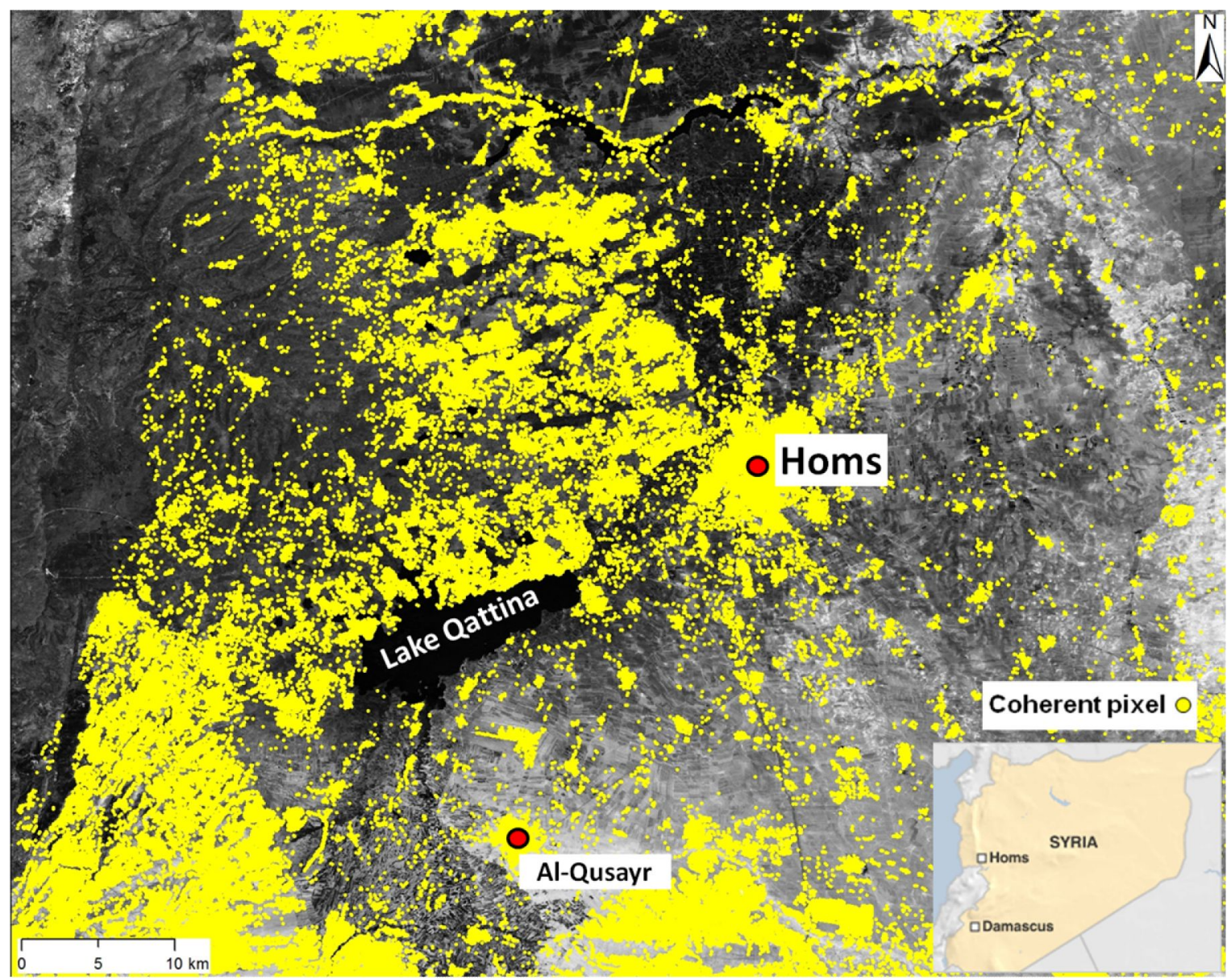

Figure 1. Spatial distribution of coherent pixels obtained from low-pass SBAS processing of ENVISAT descending data (2002-2010) over the region of Homs, western Syria, overlapped onto Landsat mosaic (2005). 


\section{6. ... TO HR X-BAND IMAGERY, TOWARDS THE SENTINELS}

Our proof-of-concept of the Sentinels' capability to support monitoring activities of areas in conflict focuses on the demonstration of what Sentinel-1A can provide on a routine basis with the StripMap beam mode.

We compare pairs of 3-m resolution VV SM TerraSAR$\mathrm{X}$ and TanDEM-X acquisitions acquired along orbit 39 and ascending passes over Homs, and implement the amplitude change detection approach presented in [6]. Damages and war-related alteration that occurred between August 2009 (prior to) and December 2014 (after major impacts of the civil war) are clearly highlighted within the urban setting of Homs (Fig. 2ac). These include military blockages (Fig. 3) and excavations (Fig. 2b). Dependently on the time window considered, the interpretation of the amplitude signal changes needs to be driven by the operator, e.g. in areas of pre-war modifications such as intentional building demolitions (Fig. 4).

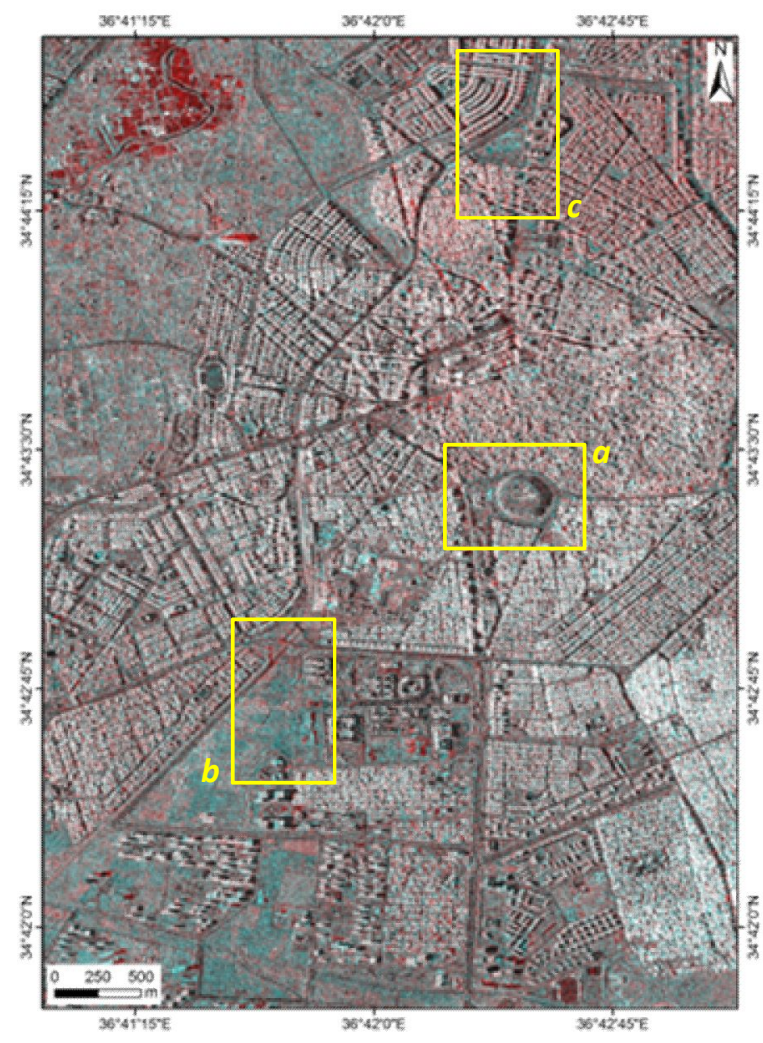

Figure 2. RC colour composite of 17/08/2009 and 05/12/2014 VV SM TSX over Homs, Syria (@ DLR 2014-2015), with examples of damages and changes in the urban setting: (a) Homs Tell with evidence of military blockage; (b) trenches and embankments in the area of Homs University; (c) Area of pre-war building demolition, northern quarter of Homs.

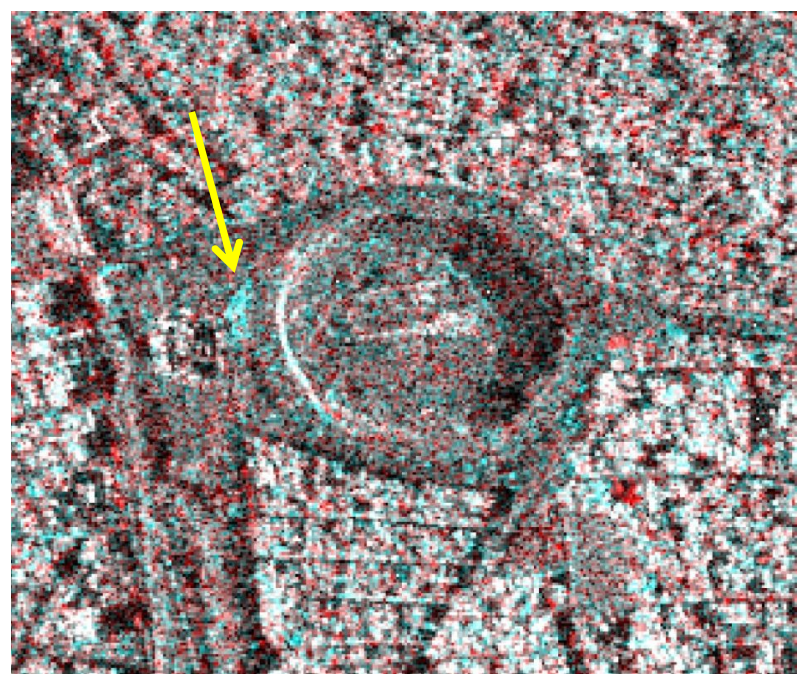

Figure 3. Homs Tell (cf. box a. in Fig. 2). The cyan spot in front of the western side of the tell (yellow arrow) indicates the surface effects of a military blockage () DLR 2014-2015).

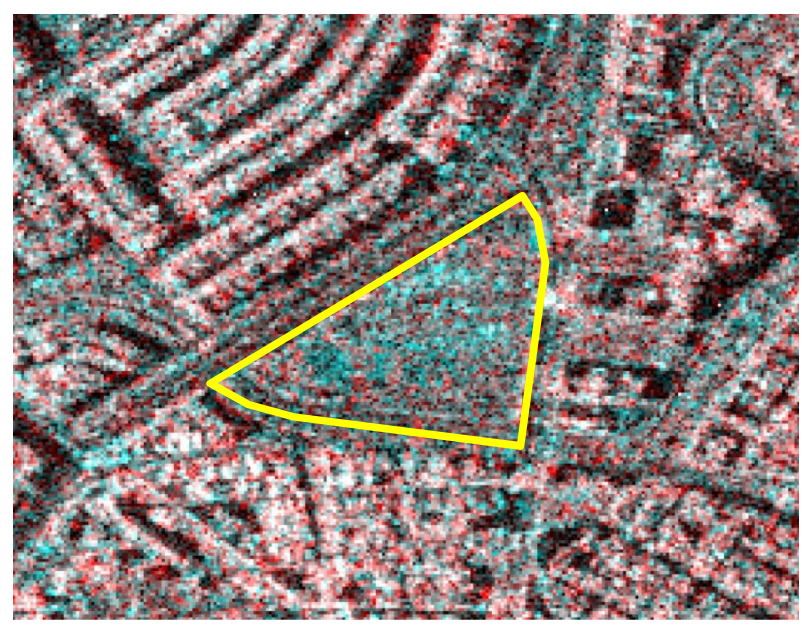

Figure 4. Zoomed view of a northern sector of Homs, where the $\sigma^{0}$ change pattern is due to pre-war building demolition (cf. box c. in Fig. 2; (C) DLR 2014-2015).

\section{ACKNOWLEDGMENTS}

This research is led by D. Tapete, supported by a European Union COFUND/Durham Junior Research Fellowship [under EU grant agreement no. 267209].

ENVISAT ASAR data were made available through ESA Cat-1 project Id.28439. TerraSAR-X and TanDEM-X data are sourced from DLR via the TSXNew-Modes-2013 LAN2377.

The authors dedicate this paper to the memory of Prof. Tony Wilkinson, Department of Archaeology, Durham University, who encouraged the use of SAR on Syrian heritage with enthusiasm and farsighted vision. 


\section{REFERENCES}

1. Casana, J. \& Panahipour, M. (2014). Notes on a Disappearing Past. Satellite-Based Monitoring of Looting and Damage to Archaeological Sites in Syria. Journal of Eastern Mediterranean Archaeology and Heritage Studies 2(2), 128-151.

2. Lasaponara, R., Danese, M. \& Masini, N. (2012). Satellite-Based Monitoring of Archaeological Looting in Peru, Springer Netherlands, pp177193.

3. Tapete, D., Cigna, F., Masini, N. \& Lasaponara, R. (2013). Prospection and Monitoring of the Archaeological Heritage of Nasca, Peru, with ENVISAT ASAR. Archaeol. Prospect. 20(2), 133-147.

4. Berardino, P., Fornaro, G., Lanari, R. \& Sansosti, E. (2002). A new algorithm for surface deformation monitoring based on small baseline differential SAR interferograms. IEEE Trans. Geosci. Remote Sens. 40(11), 2375-2383.

5. Tapete, D., Cigna, F. \& Sowter, A. (2015). Small BAseline Subset (SBAS) pixel density vs. geology and land use in semi-arid regions in Syria. In Geoscience and Remote Sensing Symposium (IGARSS), 2015 IEEE International, Milan, Italy, pp4.

6. Cigna, F., Tapete, D., Lasaponara, R. \& Masini, N. (2013). Amplitude Change Detection with ENVISAT ASAR to Image the Cultural Landscape of the Nasca Region, Peru. Archaeol. Prospect. 20(2), 117-131. 